\title{
Microarray Analysis of Retroviral Restriction Factor Gene Expression in Response to Porcine Endogenous Retrovirus Infection
}

\author{
URSZULA MAZUREK ${ }^{1}$, MALGORZATA W. KIMSA', BARBARA STRZALKA-MROZIK', \\ MAGDALENA C. KIMSA ${ }^{1 *}$, CELINA KRUSZNIEWSKA-RAJS ${ }^{1}$, JOANNA GOLA ${ }^{1}$, \\ JOLANTA ADAMSKA ${ }^{1}$ and MAGDALENA TWARDOCH ${ }^{1}$ \\ ${ }^{1}$ Department of Molecular Biology, Medical University of Silesia, \\ School of Pharmacy with the Division of Medical Analytics, Sosnowiec, Poland
}

Submitted 16 May 2013, revised 9 December 2013, accepted 12 May 2014

\author{
Abstract
}

\begin{abstract}
Microarray analysis has been used for screening genes involved in specific biological processes. Many studies have shown that restriction factors may play an important role in xenotransplantation safety, but it is still unclear whether porcine endogenous retroviruses (PERVs) may be inhibited by these factors. Therefore, the present study focused on the microarray analysis retroviral restriction factors gene expression in normal human dermal fibroblasts (NHDFs) in response to PERVs. PERV infectivity was analyzed using a co-culture system of NHDFs and porcine kidney epithelial cells (PK15 cell line). Detection of the copy number of PERV A, PERV B DNA and PERV A, PERV B RNA was performed using real-time Q-PCR and QRT-PCR. The expression of retroviral restriction factor genes was compared between PERV-infected and uninfected NHDF cells using oligonucleotide microarray. The up-regulated transcripts were recorded for two differentially expressed genes (TRIM1, TRIM16) with the use of GeneSpring platform and Significance Analysis of Microarrays. In conclusion, our results suggest that the TRIM family may play an important role in innate immunity to PERV infection. These results can allow a better understanding of restriction mechanism of PERV infection and probably design molecularly targeted therapies in the future. Moreover, knowledge of retroviral restriction factor gene expression in human cells may help to uncover strategies for determining their exact function. Microarray analyses seem to be promising in biological and biomedical studies, however, these results should be further confirmed by research conducted at the protein level.
\end{abstract}

Ke y words: porcine endogenous retroviruses, retroviral restriction factors, oligonucleotide microarray

\section{Introduction}

The microarray is an advanced molecular biological technology which allows for the study of gene expression on a global level. This method has been used particularly for screening genes involved in specific biological processes such as pathogenesis of diseases or responses to environmental stimuli (Slonim and Yanai, 2009). During recent years, a lot of methods have been suggested for microarray data analysis, however the interpretation of these data is still a very challenging task (Chuaqui et al., 2002; Nguyen et al., 2002; Verducci et al., 2006).

Currently, experimental xenotransplantations using pig cells, tissues or organs are an interesting object of many studies (Dinsmore et al., 2000; Elliott et al., 2000; Takeuchi and Weiss 2000; Nicuolo et al., 2010). However, the transmission of infectious agents between species via a xenograft is possible (Michaels, 1998). Most microorganisms may be eliminated by pathogen- free breeding of the donor animals, whereas porcine endogenous retroviruses (PERVs) cannot, since these are integrated into the genomes of all pigs (Liu et al., 2011). According to PERV tropism, three subgroups can be distinguished: PERV-A and PERV-B, which can infect human cells in vitro, and PERV-C, which can infect only pig cells (Takeuchi et al., 1998; Moalic et al., 2006). Their pathogenic potential may be similar to that associated with exogenous gammaretroviruses, close relatives of PERV, such as feline leukemia virus, murine leukemia virus or and gibbon ape leukemia virus, which are able to induce tumors and immunodeficiencies in the infected host (Moalic et al., 2006).

The permissiveness of a host cell to viral infection can be determined by the presence or absence of restriction factors. Replication of retroviruses depends on the balance between cellular cofactors and internal antiviral restriction factors (Mous et al., 2012). The latter include: tripartite motif (TRIM) protein family, apolipoprotein B mRNA-editing catalytic polypeptides (APOBEC),

\footnotetext{
* Corresponding author: M.C. Kimsa, Department of Food and Nutrition, Medical University of Silesia, School of Pharmacy with the Division of Medical Analytics, Jedności 8, 41-200 Sosnowiec, Poland; phone: +48 3236410 26; fax: +48 3236410 20, e-mail address: magdakimsa@gmail.com
} 
bone marrow stromal cell antigen 2 (BST-2, tetherin), sterile alpha motif and HD domain 1 (SAMHD1) or zinc finger antiviral protein (ZAP) (Meije et al., 2010; Laguette and Benkirane, 2012).

Recent studies have shown that these factors may also play an important role in safety of xenotransplantation (Meije et al., 2010), but it is still unclear whether PERV s may be inhibited by these factors (Abudu et al., 2006, Jónsson et al., 2007). Therefore, the present study focused on the microarray analysis retroviral restriction factors gene expression in normal human dermal fibroblasts in response to porcine endogenous retroviruses.

\section{Experimental}

\section{Materials and Methods}

Cell culture conditions. Normal human dermal fibroblasts (NHDF cell line) were obtained from Clonetics (CC-2511; San Diego, CA, USA) and routinely maintained in FBM medium (Fibroblast Basal Medium, Lonza, Basel, Switzerland), supplemented with a human fibroblasts growth factor-basic (hFGF-B), insulin and gentamicin $\left(\mathrm{FGM}^{\mathrm{TM}}\right.$ SingleQuots ${ }^{\mathrm{TM}}$; Lonza, Basel, Switzerland) at $37^{\circ} \mathrm{C}$ in a $5 \% \mathrm{CO}_{2}$ incubator (Direct Heat CO2; Thermo Scientific, Waltham, MA, USA).

Normal porcine kidney epithelial cells (PK15 cell line) were obtained from the American Type Culture Collection (ATCC CCL-33) and routinely maintained in the DMEM medium (Dulbecco's Modified Eagle Medium; Lonza, Basel, Switzerland), supplemented with $10 \%$ fetal bovine serum (FBS; Lonza, Basel, Switzerland) and gentamicin $25 \mathrm{mg} / 100 \mathrm{ml}$ (Lonza, Basel, Switzerland) at $37^{\circ} \mathrm{C}$ in a $5 \% \mathrm{CO}_{2}$ incubator (Direct Heat CO2; Thermo Scientific, Waltham, MA, USA).

Both, the cell number and viability were monitored by cell counting in the Bürker chamber, after staining them with $0.2 \%$ trypan blue (Biological Industries, Beit HaEmek, Israel). The experiment was performed on cells in the logarithmic phase of growth under condition of $\geq 98 \%$ viability assessed by trypan blue exclusion.

PERV transmission assay by co-culture technique. PERV infectivity was analyzed in a co-culture system. NHDF cells were cultured into 6-well culture plates with inserts (Nunc, Wiesbaden, Germany) at density of $1 \times 10^{5}$ cells per well. The PK15 cells were seeded into inserts (Greiner Bio-One, Wemmel, Belgium) at density of $5 \times 10^{4}$ cells per insert. The co-cultures were maintained for five days and then, after changing the medium, the human cells were kept in monoculture for one day in order to exclude that the cell response is related to co-cultivation of porcine and human cells. Next, the cell monolayer were washed with PBS. Cells were pelleted and frozen at $-70^{\circ} \mathrm{C}$ for 24 hours until nucleic acids extraction.

Deoxyribonucleic and ribonucleic acid extraction. Genomic DNA was isolated from harvested cells using a salting out extraction method (CyganekNiemiec et al., 2012). Total RNA was extracted using a TRIzol reagent (Invitrogen, Carlsbad, CA), according to the manufacturer's instructions. RNA extracts were treated with DNase I (RNeasy Mini Kit, Qiagen, Valencia, CA) according to the manufacturer's instructions. The quality of extracts was checked electrophoretically using $0.9 \%$ agarose gel stained with ethidium bromide (Sigma-Aldrich, St. Louis, MO). The results were analyzed and recorded using the 1D Bas-Sys gel documentation system (Biotech-Fisher, Perth, Australia). Nucleic acids concentration was determined using a GeneQuant II RNA/DNA spectrophotometer (Pharmacia Biotech, Cambridge, UK).

Real-time Q-PCR and QRT-PCR assay. Detection of the copy number of PERV A, PERV B DNA and PERV A, PERV B RNA was performed as described previously (Cyganek-Niemiec et al., 2012; Kimsa et al., 2012). Since the detection of PERV sequences in the infected NHDF cells could depend on the presence of residual pig cells, specific detection of the porcine cellular GAPDH and $m t D N A$ genes was carried out. $h G A P D H$ was also included as an endogenous positive control of amplification and integrity of extracts. PK15 cells were used as a positive control for PERV A and PERV B sequences.

The analysis was performed using an Opticon ${ }^{\mathrm{Tm}}$ DNA Engine Continuous Fluorescence Detector (MJ Research, Watertown, MA) and SYBR Green I chemistry (SYBR Green QuantiTect PCR Kit and SYBR Green Quantitect RT-PCR Kit; QIAGEN, Valencia, CA). All samples were tested in triplicate. Oligonucleotide primers specific for PERV A, PERV B, mtDNA, pGAPDH, hGAPDH were described previously by Bösch et al. (2000), Moon et al. (2010), Machnik et al. (2010) and Strzalka-Mrozik et al. (2010), respectively (Table I).

The thermal profile for Q-PCR was as follows: polymerase activation at $95^{\circ} \mathrm{C}$ for $15 \mathrm{~min}$ and then 40 cycles consisting of the following temperatures and time intervals: $94^{\circ} \mathrm{C}$ for $30 \mathrm{~s}, 65^{\circ} \mathrm{C}$ for $45 \mathrm{~s}$ and $72^{\circ} \mathrm{C}$ for $40 \mathrm{~s}$. The thermal profile for one-step QRT-PCR was as follows: reverse transcription at $50^{\circ} \mathrm{C}$ for $30 \mathrm{~min}$, polymerase activation at $95^{\circ} \mathrm{C}$ for $15 \mathrm{~min}$ and then 30 cycles consisting of the following temperatures and time intervals: $94^{\circ} \mathrm{C}$ for $30 \mathrm{~s}, 65^{\circ} \mathrm{C}$ for $45 \mathrm{~s}$ and $72^{\circ} \mathrm{C}$ for $40 \mathrm{~s}$.

The point at which a PCR product is first detected above a fixed threshold, termed a cycle threshold (Ct), was determined for each sample. To quantify the results obtained by PCR and RT-PCR, a standard curve method was used, described previously by CyganekNiemiec et al. (2012) and Strzalka-Mrozik et al. (2010), 
Table I

Characteristics of primers used for real-time Q-PCR and QRT-PCR

\begin{tabular}{|c|c|c|c|}
\hline Gene & Sequence of primers & $\begin{array}{l}\text { Length of amplicon } \\
\text { (bp) })^{\mathrm{a}}\end{array}$ & $\begin{array}{c}\mathrm{Tm} \\
\left({ }^{\circ} \mathrm{C}\right)^{\mathrm{b}}\end{array}$ \\
\hline PERV env A & $\begin{array}{l}\mathrm{F}^{\mathrm{c}}: \text { 5'-GAGATGGAAAGATTGGCAACAGCG-3' } \\
\mathrm{R}^{\mathrm{d}}: \text { 5'-AGTGATGTTAGGCTCAGTGGGGAC-3' }^{\prime}\end{array}$ & 364 & 80.0 \\
\hline PERV env B & $\begin{array}{l}\text { F: 5'-AATTCTCCTTTGTCAATTCCGGCCC-3 } \\
\text { R: 5'-CCAGTACTTTATCGGGTCCCACTG-3' }\end{array}$ & 270 & 81.0 \\
\hline$m t D N A$ & $\begin{array}{l}\text { F: 5'-CTGAGGAGCTACGGTCATCACAAIIIIICTATCAGCT-3 } \\
\text { R: 5'-TAGGGTTGTTGGATCCGGTTTCIIIIGGAATAGGA-3' }\end{array}$ & 210 & 80.4 \\
\hline pGAPDH & $\begin{array}{l}\text { F: 5'-TGTCGCCATCAATGACCCC-3' } \\
\text { R: 5'-TGACAAGCTTCCCATTCTC-3' }\end{array}$ & 295 & 80.1 \\
\hline$h G A P D H$ & $\begin{array}{l}\text { F: 5'-GAAGGTGAAGGTCGGAGTC-3' } \\
\text { R: 5'-GAAGATGGTGATGGGATTC-3' }\end{array}$ & 226 & 80.0 \\
\hline
\end{tabular}

${ }^{\mathrm{a}} \mathrm{bp}$ - base pairs, ${ }^{\mathrm{b}} \mathrm{Tm}$ - melting temperature, ${ }^{\mathrm{C}} \mathrm{F}$ - forward, ${ }^{\mathrm{d}} \mathrm{R}$ - reverse, ${ }^{\mathrm{e}} \mathrm{I}$ - inosine bases

respectively. PCR products were separated on $6 \%$ polyacrylamide gels and visualized with silver salts.

The obtained results of PERV DNA and RNA copy numbers were recalculated per 1000 cells.

Oligonucleotide microarray analysis. Total RNA was reversely transcribed and then the synthesis of biotynylated aRNA with the use of GeneChip 3' IVT Express Kit (Affymetrix, Ca, USA) was performed. aRNA was fragmented with the use of GeneChip 3' IVT Express Kit (Affymetrix, Ca, USA) and hybridized with the HG-U133A 2.0 (Affymetrix, Ca, USA). Staining with streptavidin-FITC was performed according to the manufacturer's instructions (Affymetrix, Ca, USA). Fluorescence intensity was measured with the use of Gene Chip Scanner $30007 \mathrm{G}$ and GeneChip ${ }^{\circledR}$ Command Console ${ }^{\varpi}$ Software (Affymetrix, Ca, USA).

Statistical analyses. Statistical analyses were performed using Statistica 9.0 software (StatSoft, Tulsa, $\mathrm{OK})$, and the level of significance was set at $\mathrm{p}<0.05$. Values were expressed as means and standard deviation (SD).

Microarray data analysis was performed with the use of GeneSpring 12.0 platform (Agilent Technologies UK Limited, South Queensferry, UK) and Significance Analysis of Microarrays (SAM). Fluorescence intensity values of all 22277 mRNA transcripts for HG-U133A 2.0 chips were simultaneously normalized using RMA algorithm (Robust Multiarray Average). Sample quality was assessed by performing 3D Principal Component Analysis (PCA), analysis of the normalized fluorescence signal values for hybridization control probes and the $3^{\prime} / 5^{\prime}$ ratios for internal controls. For further study, 95 retroviral restriction factors transcripts for 58 genes were selected from the NetAffx Analysis Center database of Affymetrix (http://www.affymetrix. com/analysis/index.affx). The normalized microarray data were used to compile a list of selected retroviral restriction factor genes whose expression appeared to be up- or down-regulated by a cutoff of at least 1.2-fold change (FC). The unpaired t test was applied to detect differentially expressed genes at p-value $<0.05$ when the analysis was performed by GeneSpring 12.0. The two class unpaired test was applied to ask if there were any differentially expressed genes when the analysis was performed by SAM with particular consideration to $\mathrm{q}$-value and score parameters. The parameter of q-value indicates the lowest false discovery rate at which the gene is called significant and its value should be lower than $5 \%$. SAM score is the $t$-statistic value and its value should be higher than 3 .

Gene Ontology analysis was carried out with the PANTHER (Protein Analysis Through Evolutionary Relationships; http://www.pantherdb.org) Classification System database to classify genes based on their biological process and molecular function.

\section{Results}

PERV infectivity. In infected cultures, PERV A DNA was detected in NHDF cells (10.14 \pm 7.6 copy number/1000 cells), whereas PERV B DNA was not found. In turn, both PERV A and PERV B RNA were observed in NHDF cells after co-cultures $(637.30 \pm 363.0$ copy number/1000 cells; $77.00 \pm 58.0$ copy number/1000 cells, respectively). All samples were found to be negative for the porcine GAPDH and $m t D N A$ what indicate that viral DNA in NHDF cells was not the result of DNA from dead disrupted PK15 cells.

Quality control on microarray samples. Based on the quality control results (PCA, hybridization controls and internal controls) there was found that all microarray samples were passed the quality criteria and were used to further analyses (data not shown).

Differential expression of retroviral restriction factor genes. The expression of retroviral restriction 


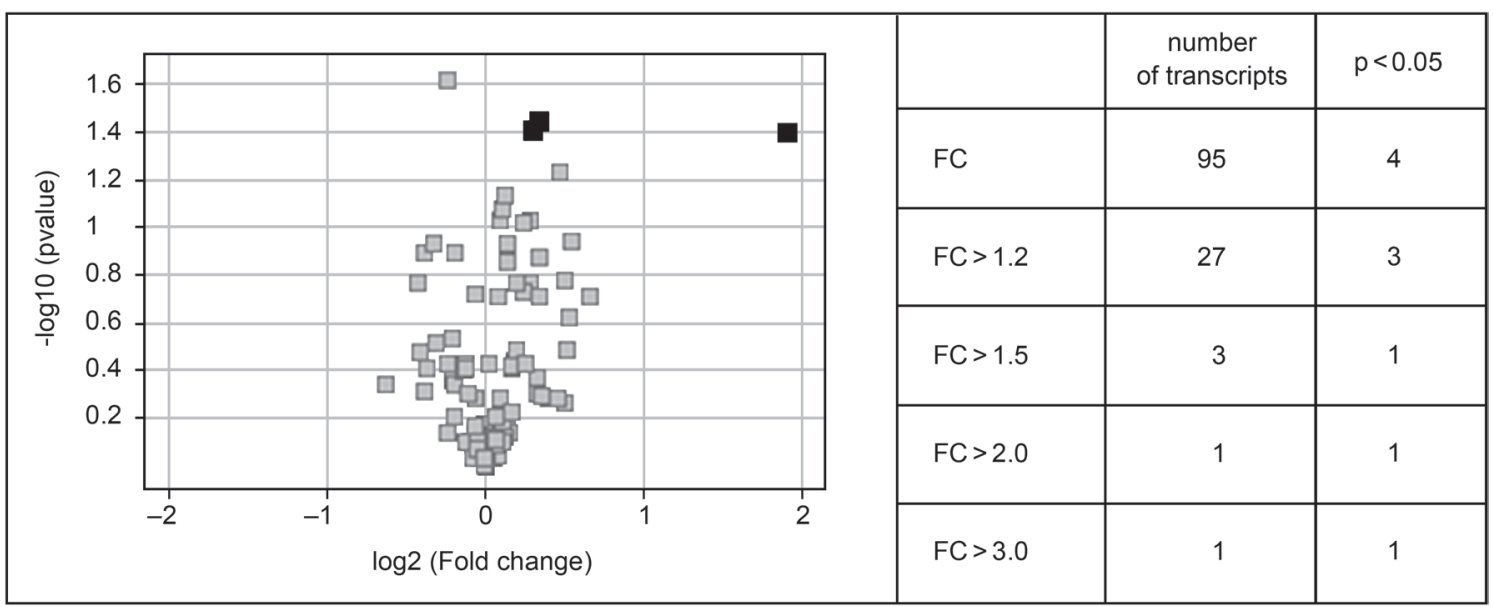

Fig. 1. Changes in gene expression between PERV-infected and control NHDF cultures on the basis of data analysis with the use of GeneSpring.

Statistical significances: $\mathrm{p}<0.05, \mathrm{t}$ test; $\mathrm{FC}$ - fold change; black - up-regulated genes with $\mathrm{p}<0.05$ and FC $>1.2$; grey - all genes with $\mathrm{p}>0.05$.

factor genes was compared between PERV-infected NHDF (NHDF PK15) and uninfected (NHDF) cells.

In the first step, the results obtained through the oligonucleotide microarray technique were analyzed using GeneSpring 12.0 platform. For 95 selected transcripts, 27 for 24 genes expressed more than 1.2-fold change in PERV-infected cells in relation to uninfected. Among these genes, only three were statistically significant differentially expressed ( $t$ test, $p<0.05$ ), out of which one gene had FC $>1.5$ (Figure 1). The up-regulated transcripts were recorded for TRIM1, TRIM16, TRIM48 (Table II).

In the next step of research, there was performed independent confirmation of data analysis with the use of SAM. The comparison between NHDF PK15 and NHDF samples, demonstrated significant differences in the expression of 15 transcripts for 14 genes (Figure 2). Nine transcripts for eight genes were statistically significant at $\mathrm{q}$-value $<5$ and score $>3$, out of which 7 genes had FC $>1.2$. Among these genes, only one gene had FC $>1.5$. The up-regulated transcripts were recorded for 5 genes (TRIM1, TRIM16, TRIM29, SAMHD1, PML) and the down-regulated transcripts were found for 2 genes (TRIM27, HNRNPAB) (Table II).

Only 2 genes (TRIM1 and TRIM16) simultaneously achieved criteria of GeneSpring and SAM for typing the genes of significant differences in transcriptional activity (Table II).

Table II

Comparison of characteristics of retroviral restriction factor genes which exhibit differential expression in PERV-infected NHDF cells versus control determined by two methods

\begin{tabular}{|c|c|c|c|c|c|c|c|}
\hline ID & Gene symbol & Gene name & $\mathrm{FC}^{\mathrm{a}}$ & p-value & FC & Score & q-value \\
\hline \multicolumn{8}{|c|}{ GeneSpring analysis } \\
\hline 220534_at & TRIM48 & tripartite motif-containing 48 & $1.23 \uparrow^{\mathrm{b}}$ & 0.039 & $\mathrm{NS}^{\mathrm{c}}$ & NS & NS \\
\hline \multicolumn{8}{|c|}{ SAM analysis } \\
\hline 202504_at & TRIM29 & tripartite motif-containing 29 & NS & NS & $1.49 \uparrow$ & 3.45 & $<0.001$ \\
\hline 211588_s_at & TRIM19 (PML) & tripartite motif-containing protein 19 & NS & NS & $1.27 \uparrow$ & 3.25 & $<0.001$ \\
\hline 204502_at & SAMHD1 & SAM domain and HD domain-containing protein 1 & NS & NS & $1.23 \uparrow$ & 3.26 & $<0.001$ \\
\hline 201277_s_at & HNRNPAB & heterogeneous nuclear ribonucleoprotein $\mathrm{A} / \mathrm{B}$ & NS & NS & $1.26 \downarrow$ & 3.19 & $<0.001$ \\
\hline 212118_at & TRIM27 & ripartite motif-containing 27 & NS & NS & $1.23 \downarrow$ & 3.89 & $<0.001$ \\
\hline \multicolumn{8}{|c|}{ GeneSpring and SAM analyses } \\
\hline 204341_at & TRIM16 & tripartite motif-containing protein 16 & $3.75 \uparrow$ & 0.039 & $4.49 \uparrow$ & 21.29 & $<0.001$ \\
\hline 209733_at & TRIM1 (MID2) & tripartite motif-containing protein 1 & $1.26 \uparrow$ & 0.036 & NS & NS & NS \\
\hline 208384_s_at & TRIM1 (MID2) & tripartite motif-containing protein 1 & NS & NS & $1.36 \uparrow$ & 5.21 & $<0.001$ \\
\hline
\end{tabular}

Genes with FC in bold achieved criteria of GeneSpring and/or SAM for typing the genes of significant differences in expression ${ }^{\mathrm{a} C C}$ - fold change

${ }^{\mathrm{b}} \uparrow, \downarrow-$ higher and lower expression in PERV-infected NHDF cells versus control

'NS - not significant 


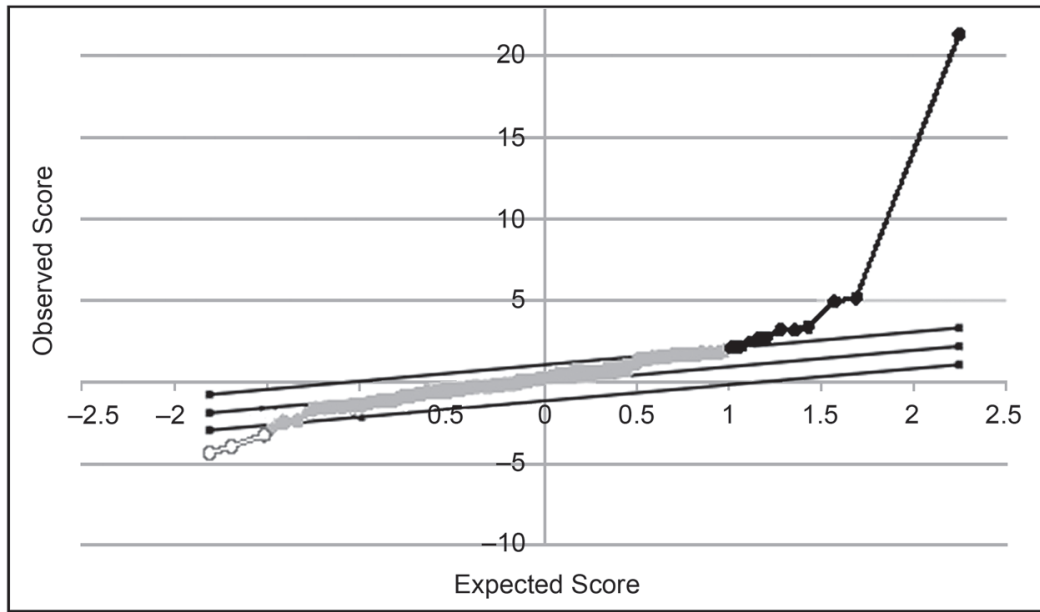

\begin{tabular}{|l|c|c|} 
& $\begin{array}{c}\text { number } \\
\text { of transcripts }\end{array}$ & $q<5$ \\
\hline Score & 15 & 15 \\
\hline Score $>3.0$ & 9 & 9 \\
\hline Score $>5.0$ & 2 & 2 \\
\hline Score $>10.0$ & 1 & 1 \\
\hline
\end{tabular}

Fig. 2. Changes in gene expression between PERV infected and control NHDF cultures on the basis of data analysis with the use of SAM. Statistical significances: score $>3.0$ and q-value $<5$; black - up-regulated genes with score $>3.0$ and q-value $<5$; white - down-regulated genes with score $>3.0$ and $\mathrm{q}$-value $<5$; grey - all genes with score $<3.0$ and q-value $<5$.

Gene ontology analysis of 10 differentially expressed transcripts (GeneSpring and SAM) identified 4 subgroups based on molecular function and 10 subgroups based on biological processes (Table III).

\section{Discussion}

In the context of pig-to-human xenotransplantation, the potential risk of zoonotic infection by porcine endogenous retroviruses: PERV A, PERV B and PERV C has been highlighted (Scobie and Takeuchi, 2009). PERV C infection appears to be only limited to pigs, whereas PERV A and PERV B can also infect human cells in vitro (Takeuchi et al., 1998; Li et al., 2006).

In the present study, provirus integration and expression of PERVs in human cells were detected by real time QPCR and QRT-PCR techniques. The presence of PERV A DNA and PERV A, PERV B RNA in NHDF cells may indicate successful PERV infection. Lack of PERV B DNA can be explained by differences

Table III

Gene Ontology annotations based on molecular function and biological process associated with differentially expressed genes classified by GeneSpring and SAM

\begin{tabular}{|l|l|}
\hline Gene symbol & Molecular Function \\
\hline HNRNPAB, TRIM1, TRIM16, TRIM29, PML & binding $\rightarrow$ protein binding; nucleic acid binding \\
\hline HNRNPAB, TRIM1, TRIM16, TRIM29, PML, SAMHD1 & $\begin{array}{l}\text { catalytic activity } \rightarrow \text { RNA splicing factor activity, transesterification } \\
\text { mechanism; hydrolase activity; ligase activity }\end{array}$ \\
\hline HNRNPAB, TRIM16, TRIM29 & $\begin{array}{l}\text { structural molecule activity } \rightarrow \text { structural constituent of cytoskeleton; } \\
\text { structural constituent of ribosome }\end{array}$ \\
\hline TRIM1, TRIM16, TRIM29, PML & $\begin{array}{l}\text { transcription regulator activity } \rightarrow \text { transcription cofactor activity; } \\
\text { transcription factor activity }\end{array}$ \\
\hline Gene symbol & Biological Process \\
\hline TRIM1, TRIM16, TRIM29, PML & cell communications $\rightarrow$ cell-cell signaling; signal transduction \\
\hline HNRNPAB, TRIM1, TRIM16, TRIM29, PML & cell cycle \\
\hline TRIM1, TRIM16, TRIM29, PML & cellular component organization $\rightarrow$ organelle organization \\
\hline HNRNPAB, TRIM1, TRIM16, TRIM29, PML, SAMHD1 & $\begin{array}{l}\text { cellular process } \rightarrow \text { cell communications; cell cycle; cellular component } \\
\text { organization }\end{array}$ \\
\hline HNRNPAB, TRIM1, TRIM16, TRIM29, PML & $\begin{array}{l}\text { developmental process } \rightarrow \text { ectoderm development; mesoderm } \\
\text { development; pattern specification process; system development }\end{array}$ \\
\hline SAMHD1 & immune system process \\
\hline HNRNPAB, TRIM1, TRIM16, TRIM29, PML & metabolic process $\rightarrow$ primary metabolic process \\
\hline HNRNPAB, TRIM1, TRIM16, TRIM29, PML & reproduction $\rightarrow$ gamete generation \\
\hline HNRNPAB, TRIM1, TRIM16, TRIM29, PML, SAMHD1 & system process $\rightarrow$ neurological system process \\
\hline TRIM1, TRIM16, TRIM29, PML & transport $\rightarrow$ protein transport; vesicle-mediated transport \\
\hline
\end{tabular}


in the sensitivity of the PCRs and the amount of transmitted viruses. Our results revealed that human dermal fibroblasts (NHDF cell line) are permissive for PERV infection, which is consistent with the findings obtained by Takeuchi et al. (1998) and Blusch et al. (2000). These authors also studied skin fibroblast cell lines, but derived from non-human primates.

The cell environment is endowed with a number of factors that actively block different stages in the pathogen life cycle. Viruses, which are unable to counter these intrinsic immunity factors in a cell, are blocked in their replication (Pineda et al., 2007, Wolf and Goff, 2008). While we were launching our study, we could not find any published reports on the gene expression in human cells infected with PERVs. Our attention focused on PERV influence on expression of internal retroviral restriction factor genes, so as to help assess the risk of PERV zoonozis during xenotransplantation. Microarray data revealed that genes associated with retroviral activity, which have altered expression profile in PERV-infected cells compared to uninfected, belonged mainly to the TRIM family. In our research, there were selected differentially expressed genes by a cutoff of at least 1.2-fold change. Many studies have also applied a fold-change cutoff from 1.2 to 4.0 FC (McCarthy and Smyth, 2009). According to the 1.2 fold change cutoff of expression alterations observed in NHDF cell, more quantitative technique and larger sample sizes will be needed to be able to investigate whether significant single genes are differentially expressed in PERV-infected versus non-infected cells. Among these genes, TRIM1, TRIM19 have been demonstrated to be antiretroviral effector proteins (Kajaste-Rudnitski et al., 2010). Yap et al. (2004) postulated that TRIM1 inhibits N-tropic murine leukemia virus (N-MLV). Uchil et al. (2008) observed that TRIM19 had a broad antiviral activities and affected the entry or release of human immunodeficiency virus 1 (HIV), murine leukemia virus (MLV), avian leukosis virus (ALV), human foamy virus, influenza A virus, human cytomegalovirus or herpes simplex type 1 .

In PERV-infected human cells, overexpression of TRIM16 was also observed. Bell et al. (2012) showed that TRIM16 homodimerized through its coiledcoil domain and heterodimerized with other TRIM family members: TRIM24, promyelocytic leukaemia (PML) protein and midline-1 (MID1). Thus, increased expression of this gene may suggest its role in antiretroviral activity.

Our research also showed that the expression of genes associated with antiretroviral activity, but not belonging to the protein of the TRIM family, was changed in PERV-infected cells. A statistically significant increase of SAMHD1 expression may confirm its role as retroviral restriction factor, which is accord- ing with results performed by Laguette and Benkirane (2012). The results of the our study revealed that expression level of HNRNPAB was lower in PERVinfected cells than in uninfected, as well Lau et al. (1997) indicated that this protein interacts specifically with a APOBEC1 and may play an important role in apoB mRNA editing. Previous reports postulated that an intrinsic immune defense is dependent on APOBEC3 protein family, which may act as restriction factors against broad range of both exogenous and endogenous retroviruses, including PERVs (Esnault et al., 2006; Wichroski et al., 2006; Jónsson et al., 2007). However, it seems that APOBEC1 also may be active against virus infection. Gee et al. (2011) demonstrated that in rat cells stably expressing APOBEC1, herpes simplex virus 1 (HSV-1) infection resulted in significantly reduced virus replication compared to that in control cells. This observation remains in agreement with a study performed by Ikeda et al. (2008), who confirmed that APOBEC1 may function as a defense mechanism, regulating retroelements in a wide range of mammalian species. Although currently activity of human APOBEC1 seems to be exclusively limited to mediate apoB mRNA editing, giving rise to two proteins with different sizes in the gastrointestinal tissues that function in transport and metabolism of lipids (Ikeda et al., 2008).

Our findings suggest that PERV infection of human cells can cause activation of cellular antiretroviral factors, mainly proteins of TRIM family. Microarray experiments result in very large amounts of data, which are difficult to interpret. The identification of differentially expressed genes is still the major goal of microarray-based expression studies. Various modern bioinformatics tools can improve the outcome of microarray analyses. Therefore in our research, two methods were used in order to typify genes which exhibit differential expression. A first approach to identify differentially expressed genes is known as the fold change estimation (FC). It evaluates the average log-ratio between two groups and considers as differentially expressed all genes that differ by more than an arbitrary cutoff (Fadiel and Naftolin, 2003; Jeanmougin et al., 2010). In the present study, first we selected genes which expression appeared to be up- or down-regulated by an arbitrary at least 1.2-fold cutoff. In the next step microarray analysis statistical tests should be used because FC does not take the variance of the samples into account, according to the Fadiel and Naftolin (2003) and Jeanmougin et al. (2010). In our research, there was performed independent confirmation of GeneSpring data analysis with the use of SAM. Thus, it can be excluded that identification of differentially expressed genes was random. However, our results demonstrate some differences among both used methods for the detection of 
differentially expressed genes. Similarly to our study, Dumeaux et al. (2006) also used two different methods in order to selection of statistically significant differentially expressed genes. These authors only revealed five differentially expressed genes by both methods.

In conclusion, our results suggest that the TRIM family may play an important role in innate immunity to PERV infection. These results can allow a better understanding of the restriction mechanism of PERV infection and probably the of design molecularly targeted therapies in the future. Moreover, knowledge of retroviral restriction factor gene expression in human cells may help to uncover strategies for determining their exact function. Microarray analyses seem to be promising in biological and biomedical studies, however, these results should be further confirmed by research conducted at protein level.

\section{Disclosure Statement}

The authors declare that there are no conflicts of interest.

\section{Acknowledgments}

This study was supported by the grant No. KNW-2-031/D/3/N from Medical University of Silesia, Katowice, Poland and by the project no. NR 120036 06, which was financed from 2009 to 2013 by the National Centre for Research and Development in Poland.

\section{Literature}

Abudu A., A. Takaori-Kondo, T. Izumi, K. Shirakawa, M. Kobayashi, A. Sasada, K. Fukunaga and T. Uchiyama. 2006. Murine retrovirus escapes from murine APOBEC3 via two distinct novel mechanisms. Curr. Biol. 16 (15): 1565-1570.

Bell J.L., A. Malyukova, J.K. Holien, J. Koach, M.W. Parker, M. Kavallaris, G.M. Marshall and B.B. Cheung. 2012. TRIM16 acts as an E3 ubiquitin ligase and can heterodimerize with other TRIM family members. PLoS One 7 (5): e37470.

Blusch J.H., C. Patience, Y. Takeuchi, C. Templin, C. Roos, K. Von Der Helm, G. Steinhoff and U. Martin. 2000. Infection of Nonhuman Primate Cells by Pig Endogenous Retrovirus. J. Virol. 74: 7687-7690.

Bösch S., C. Arnauld and A. Jestin. 2000. Study of full-length porcine endogenous retrovirus genomes with envelope gene polymorphism in a specific-pathogen-free Large White swine herd. J. Virol. 74(18): 8575-8581.

Chuaqui R.F., R.F. Bonner, C.J. Best, J.W. Gillespie, M.J. Flaig, S.M. Hewitt, J.L. Phillips, D.B. Krizman, M.A. Tangrea, M. Ahram and others. 2002. Post-analysis follow-up and validation of microarray experiments. Nat. Genet. 32: 509-514.

Cyganek-Niemiec A., B. Strzalka-Mrozik, L. Pawlus-Lachecka, J. Wszolek, J. Adamska, J. Kudrjavtseva, I. Zhuravleva, M. Kimsa, H. Okla, M. Kimsa and others. 2012. Degradation effect of diepoxide fixation on porcine endogenous retrovirus DNA in heart valves: molecular aspects. Int. J. Artif. Organs. 35 (1): 25-33.

Denner J., H.J. Schuurman and C. Patience. 2009. The International Xenotransplantation Association consensus statement on conditions for undertaking clinical trials of porcine islet products in type 1 diabetes-Chapter 5: Strategies to prevent transmission of porcine endogenous retroviruses. Xenotransplantation 16: 239-248.
Di Nicuolo G., A. D’Alessandro, B. Andria, V. Scuderi, M. Scognamiglio, A. Tammaro, A. Mancini, S. Cozzolino, E. Di Florio, A. Bracco and others. 2010. Long-term absence of porcine endogenous retrovirus infection in chronically immunosuppressed patients after treatment with the porcine cell-based Academic Medical Center bioartificial liver. Xenotransplantation 17 (6): 431-439. Dinsmore J.H., C. Manhart, R. Raineri, D.B. Jacoby and A. Moore. 2000. No evidence for infection of human cells with porcine endogenous retrovirus (PERV) after exposure to porcine fetal neuronal cells. Transplantation 70 (9): 1382-1389

Dumeaux V., Johansen J., Børresen-Dale A.L. and E. Lund. 2006. Gene expression profiling of whole-blood samples from women exposed to hormone replacement therapy. Mol. Cancer. Ther. 5 (4): 868-876.

Elliott R.B., L. Escobar, O. Garkavenko, M.C. Croxson, B.A. Schroeder, M. McGregor, G. Ferguson, N. Beckman and S. Ferguson. 2000. No evidence of infection with porcine endogenous retrovirus in recipients of encapsulated porcine islet xenografts. Cell. Transplant. 9 (6): 895-901.

Esnault C., J. Millet, O. Schwartz and T. Heidmann. 2006. Dual inhibitory effects of APOBEC family proteins on retrotransposition of mammalian endogenous retroviruses. Nucleic. Acids. Res. 34 (5): 1522-1531.

Gee P., Y. Ando, H. Kitayama, S.P. Yamamoto, Y. Kanemura, H. Ebina, Y. Kawaguchi and Y. Koyanagi. 2011. APOBEC1-mediated editing and attenuation of herpes simplex virus 1 DNA indicate that neurons have an antiviral role during herpes simplex encephalitis. J. Virol. 85(19): 9726-9736.

Jeanmougin M., A. de Reynies, L. Marisa, C. Paccard, G. Nuel and M. Guedj. 2010. Should we abandon the t-test in the analysis of gene expression microarray data: a comparison of variance modeling strategies. PLoS One 5 (9): e12336.

Jónsson S.R., R.S. LaRue, M.D. Stenglein, S.C. Fahrenkrug, V. Andrésdóttir and R.S. Harris. 2007. The restriction of zoonotic PERV transmission by human APOBEC3G. PLoS One 2 (9): e893. Kajaste-Rudnitski A., C. Pultrone, F. Marzetta, S. Ghezzi, T. Coradin and E. Vicenzi. 2010. Restriction factors of retroviral replication: the example of Tripartite Motif (TRIM) protein 5 alpha and 22. Amino Acids. 39 (1): 1-9.

Kimsa M., B. Strzalka-Mrozik, M. Kimsa, J. Adamska, J. Gola, K. Lopata and U. Mazurek. 2012. Quantitative estimation of porcine endogenous retrovirus release from PK15 cells. Pol. J. Microbiol. 61: 211-215.

Laguette N. and M. Benkirane. 2012. How SAMHD1 changes our view of viral restriction. Trends Immunol. 33 (1): 26-33.

Lau P.P., H.J. Zhu, M. Nakamuta and L. Chan. 1997. Cloning of an Apobec-1-binding protein that also interacts with apolipoprotein B mRNA and evidence for its involvement in RNA editing. J. Biol. Chem. 272 (3): 1452-1455.

Li Z., Y. Ping, L. Shengfu, Z. Yangzhi, C. Jingqiu, C.L. Youping and B. Hong. 2006. Variation of host cell tropism of porcine endogenous retroviruses expressed in chinese Banna minipig inbred. Intervirology 49: 185-191.

Liu G., Z. Li, M. Pan, M. Ge, Y. Wang and Y. Gao. 2011. Genetic prevalence of porcine endogenous retrovirus in Chinese experimental miniature pigs. Transplant Proc. 43: 2762- 2769.

Luo Y., L. Lin, L. Bolund, T.G. Jensen, C.B. Sørensen. 2012. Genetically modified pigs for biomedical research. J. Inherit. Metab. Dis. 35 (4): 695-713.

Machnik G., D. Sypniewski, S. Gałka, T. Loch, D. Sołtysik, D. Błaszczyk and I. Bednarek. 2010. Changes of syncytin I expression level in HEK293 cells line after infection buy porcine endogenous retroviruses (PERV) (in Polish). Farm. Przegl. Nauk. 12: 14-20. McCarthy D.J. and G.K. Smyth. 2009. Testing significance relative to a fold-change threshold is a TREAT. Bioinformatics 25 (6): 765-71. 
Meije Y., R.R. Tönjes and J.A. Fishman. 2010. Retroviral restriction factors and infectious risk in xenotransplantation. Am. J. Transplant. 10 (7): 1511-6.

Michaels M. 1998. Xenozoonoses and the xenotransplant recipient. Ann. NY Acad. Sci. 862: 100-104.

Moalic Y., Y. Blanchard, H. Félix and A. Jestin. 2006. Porcine endogenous retrovirus integration sites in the human genome: features in common with those of murine leukemia virus. J. Virol. 80 (22): 10980-10988.

Moon H.J., S.J. Park, H.K. Kim, S.K. Ann, S. Rho, H.O. Keum and B.K. Park. 2010. Simultaneous detection and subtyping of porcine endogenous retroviruses proviral DNA using the dual priming oligonucleotide system. J. Vet. Sci. 11 (3): 269-271.

Mous K., W. Jennes, M. Camara, M. Seydi, G. Daneau, S. Mboup, L. Kestens and X. Van Ostade. 2012. Expression analysis of LEDGF/ p75, APOBEC3G, TRIM5alpha, and tetherin in a Senegalese cohort of HIV-1-exposed seronegative individuals. PLoS One 7 (3): e33934. Nguyen D.V., A.B. Arpat, N. Wang and R.J. Carroll. 2002. DNA microarray experiments: biological and technological aspects. Biometrics 58 (4): 701-717.

Pineda M.J., B.R. Orton and J. Overbaugh. 2007. A TRIM5alphaindependent post-entry restriction to HIV-1 infection of macaque cells that is dependent on the path of entry. Virology 363 (2):310-318. Scobie L. and Y. Takeuchi. 2009. Porcine endogenous retrovirus and other viruses in xenotransplantation. Curr Opin Organ Transplant. 14 (2): 175-179.

Slonim D.K. and I. Yanai. 2009. Getting started in gene expression microarray analysis. PLoS Comput. Biol. 5 (10): e1000543.
Strzalka-Mrozik B., A. Stanik-Walentek, M. Kapral, M. Kowalczyk, J. Adamska, J. Gola and U. Mazurek. 2010. Differential expression of transforming growth factor- $\beta$ isoforms in bullous keratopathy corneas. Mol. Vis. 16: 161-166.

Takeuchi Y. and R.A. Weiss. 2000. Xenotransplantation: reappraising the risk of retroviral zoonosis. Curr. Opin. Immunol. 12(5): 504-507.

Takeuchi Y., C. Patience, S. Magre, R.A. Weiss, P.T. Banerjee, P. Le Tissier and J.P. Stoye. 1998. Host Range and Interference Studies of Three Classes of Pig Endogenous Retrovirus. J. Virol. 72: 9986-9991.

Uchil P.D., B.D. Quinlan, W.T. Chan, J.M. Luna and W. Mothes. 2008. TRIM E3 ligases interfere with early and late stages of the retroviral life cycle. PLoS Pathog. 4 (2): e16.

Uchil P.D., B.D. Quinlan, W.T. Chan, J.M. Luna and W. Mothes. 2008. TRIM E3 ligases interfere with early and late stages of the retroviral life cycle. PLoS Pathog. 4 (2): e16.

Verducci J.S., V.F. Melfi, S. Lin, Z. Wang, S. Roy and C.K. Sen. 2006. Microarray analysis of gene expression: considerations in data mining and statistical treatment. Physiol. Genomics. 25 (3): 355-363. Wichroski M.J., G.B. Robb and T.M. Rana. 2006. Human retroviral host restriction factors $\mathrm{APOBEC} 3 \mathrm{G}$ and $\mathrm{APOBEC} 3 \mathrm{~F}$ localize to mRNA processing bodies. PLoS Pathog. 2 (5): e41.

Wolf D. and S.P. Goff. 2008. Host restriction factors blocking retroviral replication. Annu. Rev. Genet. 42: 143-163.

Yap M.W., S. Nisole, C. Lynch and J.P. Stoye. 2004. Trim5alpha protein restricts both HIV-1 and murine leukemia virus. Proc. Natl. Acad. Sci. USA 101 (29): 10786-10791. 